\title{
To flex or not to flex? Flexible work arrangements amongst software developers in an emerging economy
}

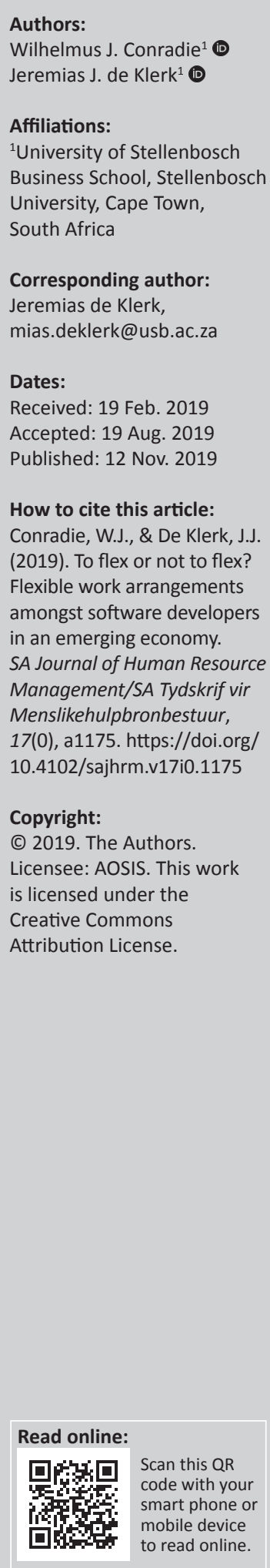

Orientation: Professional workers increasingly have the ability to do their work outside normal working hours, while being away from the workplace or from the comfort of their homes. Advancements in technology have made flexible work arrangements (FWAs) much easier and viable for corporates to consider.

Research purpose: Although research mostly confirms the benefits of FWAs, research on the outcomes of FWAs is somewhat inconclusive and sometimes contradicting, both within and across developed and emerging economies.

Motivation for the study: It is important to advance our understanding of the use of FWAs and their outcomes so that organisations in emerging economies have a valid basis for considering the implementation of FWAs.

Research approach/design and method: This study applied survey-based research to investigate the use and outcome of two of the most common FWAs - flexible working-time hours and telecommuting - amongst software developers in an emerging economy.

Main findings: The results indicate that employers in South African software development sector have largely adopted FWAs, and that developers use flexible working arrangements and perceive them to be beneficial for themselves and their organisations. The study results confirm that FWAs do not correlate with fewer working hours but do correlate with increased levels of both engagement and performance.

Practical/managerial implications: The findings are important in the light of critical shortage of and the resulting high pressure on software developers. Employers in emerging economies such as South Africa could seriously consider implementing FWAs, can probably do so with confidence and are likely to receive support from their staff.

Contribution/value-add: The findings of this study are significant because they confirm that the workplace flexibility provided by FWA is effective, also in a developing economy such as South Africa.

Keywords: engagement; flexible work arrangements; flexitime; performance; telecommute.

\section{Introduction}

Workers are increasingly looking for working time flexibility, and one of the challenges that organisations face is with regard to combining their business requirements with employees' needs for flexibility. Flexible working arrangements (FWAs) refer to employment practices that provide employees with less rigid structures to execute their daily work and to operate in (Masuda et al., 2012).

Research results mostly indicate that not only are FWAs popular but that implementation mostly yields many important positive work outcomes, such as high performance (De Menezes \& Kelliher, 2017) and increased engagement (Anitha, 2014; Bailey, Madden, Alfes, \& Fletcher, 2017). However, FWAs are not a panacea or without challenges and a major issue underlying research on FWAs is whether the outcomes are universally applicable, or contingent on particular contexts (Peretz, Fried, \& Levi, 2018). Indeed, research is somewhat inconclusive, and most research on FWAs has been conducted in Western countries and developed economies (Bloom, Liang, Roberts, \& Ying, 2015; Peretz et al., 2018). However, research in emerging economies (especially in Asian countries) often present contradicting results (Croucher \& Rizov, 2014; Onken-Menge, Nüesch, \& Kröll, 2018; Vahle-Hinz, Kirschner, \& Thomson, 2013). 
From both a theoretical and an application perspective, it is important to advance our understanding of the use of FWAs and their outcomes within and across nations and cultural contexts so that organisations have a valid basis for considering the implementation of FWAs (Peretz et al., 2018). With FWAs pervasive in the software development industry globally (Boell, Cecez-Kecmanovic, \& Campbell, 2016; Johns \& Gratton, 2013), it is particularly important to understand its adoption and outcomes. A study on FWAs with a sample from an emerging economy such as South Africa can provide unique insights into outcomes of workplace flexibility in this context.

In this study, we assessed the availability and the usage of FWAs in the software development sector of South Africa, its perceived advantage from an employee's perspective and its relationship with performance and engagement. Flexible work arrangements are restricted to two of its most popular aspects, namely, flexitime (allowing employees flexibility in working hour options) (De Menezes \& Kelliher, 2017) and telecommuting (commonly known as working remotely or 'work from home') (Onken-Menge et al., 2018; Peretz et al., 2018; Spreitzer, Cameron, \& Garrett, 2017). From the literature study, conceptualisations were developed about FWAs in the South African context, and in particular the software development industry, from which four specific research hypotheses were developed. A sample of 260 individual respondents provided information on the usage of FWAs, their perceptions on whether FWAs are beneficial and its relationships with tenure, working hours, engagement and performance. The hypotheses were assessed through Exploratory Factor Analysis (EFA), Confirmatory Factor Analysis (CFA), $t$-tests and Stepwise Multiple Regression. Results and recommendations are discussed.

\section{Literature review}

\section{The rise and prevalence of flexible work arrangements}

With the advancements in information and communication technology and the widespread adoption of the Internet, new working arrangements have become a popular possibility (Allen, Golden, \& Shockley, 2015). Today's workforce actively seeks out the opportunity to work more flexibly and the provision and the usage of FWAs are increasing rapidly (Regus, 2017). Flexible work arrangements can be defined as formal or informal arrangements, which allow employees some flexibility and choice to control and readjust their working hours and/or spatial location of work (Campbell, 2015; Ciarniene \& Vienazindiene, 2018).

Today's workforce is increasingly composed of workers who actively want more freedom of choice and seek out the opportunity to work more flexibly in terms of time and location (Pitt-Catsouphes, Matz-Costa, \& Besen, 2012; Regus, 2017). Providing the experience choice and flexibility at work engages employees psychologically by providing elevated experiences of psychological and physiological job resources (Pitt-Catsouphes et al., 2012). Psychological and physiological job resources include 'physical, psychological, social or organisational aspects that either/or (1) reduce job demands and the associated physiological and psychological costs; (2) are functional in achieving work goals' (Schaufeli \& Bakker, 2004, p. 296). Flexible work arrangements apply directly to both parts of the definition. It enables individuals to cope better with the competing stresses between home and work demands by improving employees' experience of the interaction between their work and personal life (home) roles (Campbell, 2015; Weale, Wells, \& Oakman, 2017). Flexible work arrangements to address the psychological and physical job resources include many different working arrangements, such as flexitime (allowing employees flexibility in working hour options) (De Menezes \& Kelliher, 2017), telecommuting or teleworking (working remotely or 'work from home'), job sharing and a variety of temporary work contract arrangements (Berkery, Morley, Tiernan, Purtill, \& Parry, 2017). Two of the most popular types of FWAs for full-time employees appear to be flexitime and telecommuting (Onken-Menge et al., 2018; Peretz et al., 2018; Spreitzer et al., 2017).

Some of the biggest drivers behind the growth in FWAs include employees' need for better work-life balance (Spreitzer et al., 2017), a drive to resolve family-work conflict (Putnam, Myers, \& Gailliard, 2014) and a desire to reduce the time 'wasted' time in commuting (Regus, 2017). In response to these trends and needs, many employers attempt to provide employees with more freedom and flexibility, without compromising on the organisation's interests (Regus, 2017). Especially knowledge workers are increasingly becoming able and enabled to complete work without being physically present at the office and to perform tasks from anywhere and at any time (Johns \& Gratton, 2013; Lee \& De Kok, 2016). The potential of the flexible workplace is now a reality, giving employers more options to consider to improve workplace practices by implementing FWAs (Allen, Johnson, Kiburz, \& Shockley, 2013). Employers worldwide have increasingly adopted FWAs in an attempt to attract and retain talented employees and enhance their competitiveness (Peretz et al., 2018; Stavrou \& Kilaniotis, 2010).

\section{Outcomes of flexible work arrangements}

Research indicates that FWAs are popular, that is, its implementation is inexpensive and mostly yields positive benefits (Berkery et al., 2017; Regus, 2017). A range of empirical studies on FWAs attest to the positive work outcomes related to its implementation and usage. Some of these studies are summarised in Table 1.

Table 1 shows that FWAs are consistently related to a broad spectrum of positive work outcomes. Flexible work arrangements tend to be attractive from both an organisational point of view and an employee point of view. Ayman, Ashoush and Younis (2015) argue that organisations value outcomes such as reduced turnover rates, lower absenteeism, increased loyalty and productivity, and more positive work attitudes. Similarly, employees value more balance between work and family demands, lowered workload stress and 
TABLE 1: Benefits of flexible work arrangements.

\begin{tabular}{|c|c|}
\hline Outcomes & Studies (researchers) \\
\hline Commitment & $\begin{array}{l}\text { Chen and Fulmer (2016, 2018); De Menezes and Kelliher } \\
\text { (2017); McNall, Masuda and Nicklin (2010); Onken-Menge } \\
\text { et al. (2018); Peretz et al. (2018) }\end{array}$ \\
\hline Reduced stress & Allen et al. (2015); Halpern (2005) \\
\hline $\begin{array}{l}\text { Productivity } \\
\text { improvement }\end{array}$ & $\begin{array}{l}\text { Berkery et al. (2017); Bloom et al. (2015); Coenen and } \\
\text { Kok (2014) }\end{array}$ \\
\hline $\begin{array}{l}\text { Experienced work-life } \\
\text { balance }\end{array}$ & $\begin{array}{l}\text { Bessa and Tomlinson (2017); Dizaho, Salleh and Abdullah } \\
\text { (2017); Regus (2017); Ter Hoeven and Van Zoonen (2015) }\end{array}$ \\
\hline $\begin{array}{l}\text { Reduced family-work } \\
\text { conflict }\end{array}$ & $\begin{array}{l}\text { Bessa and Tomlinson (2017); Masuda et al. (2012); } \\
\text { Regus (2017) }\end{array}$ \\
\hline Psychological health & $\begin{array}{l}\text { Haar, Russo, Suñe and Ollier-Malaterre (2014); } \\
\text { Subramaniam, Tan, Maniam and Ali (2013); Ter Hoeven and } \\
\text { Van Zoonen (2015); Timms et al. (2015) }\end{array}$ \\
\hline $\begin{array}{l}\text { Organisational } \\
\text { attractiveness }\end{array}$ & $\begin{array}{l}\text { Naidoo and Kasiram (2003); Onken-Menge et al. (2018); } \\
\text { Thompson, Payne and Taylor (2015) }\end{array}$ \\
\hline Reduced absenteeism & $\begin{array}{l}\text { Berkery et al. (2017); De Menezes and Kelliher (2011); } \\
\text { Halpern (2005); Peretz et al. (2018); Stavrou (2005) }\end{array}$ \\
\hline Job satisfaction & $\begin{array}{l}\text { Bessa and Tomlinson (2017); Chen and Fulmer (2016, } \\
\text { 2018); De Menezes and Kelliher (2011); De Menezes and } \\
\text { Kelliher (2017); Haar et al. (2014); McNall et al. (2010) }\end{array}$ \\
\hline $\begin{array}{l}\text { Reduced turnover or } \\
\text { turnover intentions }\end{array}$ & $\begin{array}{l}\text { Berkery et al. (2017); Masuda et al. (2012); McNall et al. } \\
\text { (2010); Onken-Menge et al. (2018); Peretz et al. (2018); } \\
\text { Stavrou and Kilaniotis (2010); Timms et al. (2015) }\end{array}$ \\
\hline Performance metrics & $\begin{array}{l}\text { Abba (2018); Bessa and Tomlinson (2017); Chen and } \\
\text { Fulmer (2016); De Menezes and Kelliher (2011); Opuko } \\
\text { and Munjuri (2017); Rabl, Jayasinghe, Gerhart and } \\
\text { Kühlmann (2014); Stavrou (2005) }\end{array}$ \\
\hline Employee engagement & $\begin{array}{l}\text { Allen et al. (2015); Anitha (2014); Bailey et al. (2017); Bal } \\
\text { and De Lange (2015); Timms et al. (2015) }\end{array}$ \\
\hline
\end{tabular}

improved quality of work life. Despite these positive outcomes, access to and use of FWAs vary widely within and across organisational and national contexts as explicated later (Bessa \& Tomlinson, 2017).

Interestingly, not only do specific FWAs yield the results indicated in Table 1 independently or in isolation but also tend to render an even stronger result if more than one type is applied, for example, the typical combination of flexitime with telecommuting (Thompson et al., 2015), which tends to act as a single bundle (Peretz et al., 2018; Stavrou, 2005). As such, many empirical studies tend to combine different types of FWAs as a single construct (Chen \& Fulmer, 2018).

However, the implementation of FWAs is not a panacea for workplace problems. Notwithstanding research largely indicating positive outcomes of FWAs, empirical results on the relationship between FWAs and well-being are somewhat inconclusive and sometimes contradicting to the benefits listed in Table 1 (Vahle-Hinz et al., 2013). For instance, it was found that teleworking can promote isolation and lack of support experienced from the organisation (Croucher \& Rizov, 2014), increased stress as work and home life become inseparable (Baard \& Thomas, 2010) and reduced well-being through increased workload (Onken-Menge et al., 2018; Regus, 2017; Ter Hoeven \& Van Zoonen, 2015). Flexible work arrangements present coordination, control, collaboration difficulties and negative attitudes (Ayman et al., 2015). An unsupportive culture may cause stigmatisation of those who take advantage of FWAs (Den Dulk, Groeneveld, Ollier-Malaterre, \& Valcour, 2013; Putnam et al., 2014), resulting in increased stress (Vahle-Hinz et al., 2013). The need to investigate the use and outcomes of FWAs further is thus evident.

\section{Flexible work arrangements and sociocultural context}

Apart from a few exceptions, most research on FWAs has been conducted in Western countries (Bloom et al., 2015; Peretz et al., 2018). With the world representing a global economy, it is important to understand whether human resource practices such as FWAs render similar outcomes in different countries and contexts (Rabl et al., 2014). Indeed, several studies have shown that the use and outcomes of FWAs can differ significantly across nations (Kassinis \& Stavrou, 2013; Ollier-Malaterre \& Foucreault, 2017; Peretz et al., 2018; Stavrou, Parry, \& Anderson, 2015). The few studies relating to FWAs in emerging countries (mostly Asian settings) often contradict the findings from Western and developed economies (Bloom et al., 2015; Croucher \& Rizov, 2014; Ollier-Malaterre \& Foucreault, 2017; Peretz et al., 2018; Stock, Strecker, \& Bieling, 2016). Moreover, there appears not to be a predictable pattern in the outcomes of FWAs across nations and cultures, as research also found differences in the outcomes of FWAs across nations within the West (Masuda et al., 2012; Peters \& Den Dulk, 2003; Stavrou \& Kilaniotis, 2010), and between the West, the East and Latin America (Masuda et al., 2012; Stock et al., 2016), and also within Asia (Dizaho et al., 2017). The need to investigate the use and outcomes of FWAs in various specific countries and economies is evident.

\section{Flexible work arrangements and the emerging economy of South Africa}

Research on FWAs is scarce within the emerging economies of Africa. Notwithstanding, the available research found a correlation between FWAs and job performance in Kenya and Nigeria (Abba, 2018; Opuko \& Munjuri, 2017). In South Africa, FWAs have been correlated with loyalty and morale (Appiah-Mfodwa, Horwitz, Kieswetter, King, \& Solai, 2000), decreased stress and commuting time (Baard \& Thomas, 2010) and job satisfaction and work-life balance (Grobler \& De Bruyn, 2011). The availability and the use of FWAs in South Africa have been found to be particularly popular and effective in emerging multinational companies (Horwitz, 2017). Based on these (limited) results, it appears that FWAs would render positive research outcomes for South African employees, notwithstanding the potential differences in outcomes of FWAs across nations and economies that were noted previously in research.

It seems as if other contextual factors, such as the macroeconomic environment, can influence the use and outcomes of FWAs, particularly in emerging economies (Idris, 2014). In most developed economies, unemployment is low, standards of living are comparatively high and organisational work-family support is relatively common (Stock et al., 2016). This is not necessarily the case in emerging economies where unemployment rates are often high, combined with a mismatch between skills required and the generally available skill set of the working population (Ahmad, Shaw, Bown, Gardiner, \& Omar, 2015; Reddy, Bhorat, Powell, Visser, \& Arends, 2016). Indeed, this is the case in South Africa, where there is a 'structural mismatch between labour demand and supply ... in that the economy 
and labour market shows demand for high-skilled workers, but there is a surplus of low-skilled workers' (Reddy et al., 2016 , p. 9). The unemployment rate is between $25 \%$ (structured) and $35 \%$ (expanded), with $42 \%$ of the labour force having less than a grade 12 certificate and only $25 \%$ being classified as skilled workers (Reddy et al., 2016). This puts immense demands on skilled workers' working hours and pressure on organisations to curb their turnover intentions (Ahmad et al., 2015). It is thus reasonable to argue that the skilled South African workers will value the opportunity to make use of FWAs. Indeed, Naidoo and Kasiram (2003) found that South African professionals working in the United Kingdom appreciate the higher prevalence of FWAs abroad, and find them beneficial. These factors seem to imply that the skilled South African employees are likely to appreciate FWAs as being beneficial, notwithstanding research that found negative outcomes of FWAs in some emerging economies (Chandra, 2012; Idris, 2014).

\section{Flexible work arrangements and software developers in South Africa}

Within the sociocultural context of a country, the industry sector is another contextual feature likely to affect the use and outcomes of FWAs. Peretz et al. (2018) and Stavrou (2005) argue that service-oriented and private, high-tech organisations have more flexibility than manufacturing organisations and are thus better able to accommodate FWAs. In this sector, South Africa has a particular competitive advantage in the fast-growing software development market (Maseko, 2017; Quartz Africa, 2016). However, the growth of this subsector is inhibited by a substantive lack of skills and a chronic shortage of software developers (News24Wire, 2015). Many software development firms tend to be smalland medium-size private enterprises (SMEs) (Statistics South Africa, 2017), typically lacking the resources to compete with larger firms on elaborate monetary benefits. Offering benefits such as FWAs can therefore present a differentiating advantage to employers to attract and retain employees with restricted and sought-after skills (Den Dulk et al., 2013; Ross \& Ali, 2017).

Access to a fast and reliable Internet connection is a prerequisite for effective telecommuting (Regus, 2017). In many developed economies, the almost omnipresent Internet is a given, permeating most aspects of work and daily life (Regus, 2017). However, a slow or unreliable Internet connection is experienced as a major obstacle for telecommuting in many emerging economies. For instance, $92 \%$ of Brazilian workers and $33 \%$ of South African workers noted this as a major obstacle (Regus, 2017). However, even in emerging economies, the information and technology environment is suited for telecommuting, because of these workers' relative better access to a fast and reliable Internet than workers in other industries (Ross \& Ali, 2017). In some of the emerging economies where FWAs did not yield positive outcomes, it is related to the issues of trust and accountability in cultures where rigid operating hours are appreciated (Chandra, 2012; Idris, 2014). This is not the case in the software development industry where developers' commitment and the work context promote both telecommuting and flexitime (Ross \& Ali, 2017). Indeed, Nortje, Van Brakel and Rensleigh (2009) note that FWAs are popular in the South African software development sector. Because of the nature of the work context of South African software developers, it seems reasonable to expect that FWAs will be generally available to these employees and that they will make substantive use thereof.

\section{Flexible work arrangements and engagement}

The relationship between FWAs and employee engagement (as noted in Table 1) is of particular interest in South Africa, where employee engagement levels tend to be one of the lowest globally (Abbot, 2014). Engagement is a vital workplace variable as it is consistently confirmed to be a strong predictor of a range of positive work outcomes, such as high performance and low turnover intentions, high morale, enhanced commitment and involvement (Bailey et al., 2017), increased job satisfaction and commitment (Lockwood, 2007), and productivity (Böckerman \& Ilmakunnas, 2012). Engagement is defined as 'a positive, fulfilling, work-related state of mind characterised by vigour, dedication and absorption' (Schaufeli, Salanova, González-romá, \& Bakker, 2002, p. 74). Vigour is described as high levels of energy, resilience, willingness to invest effort in one's work and persistence despite difficulties (Schaufeli \& Bakker, 2004). Dedication refers to a 'sense of significance, enthusiasm, inspiration, pride and challenge' (Schaufeli \& Bakker, 2004, p. 295). Absorption refers to being fully concentrated and happily engrossed in one's work (Schaufeli \& Bakker, 2004).

Job resources have been shown to be a significant antecedent of employee engagement (Bailey et al., 2017). Amongst other aspects, job resources refer to those 'physical, psychological, social or organisational aspects that reduce job demands and the associated physiological and psychological costs' (Schaufeli \& Bakker, 2004, p. 296). One can argue that FWAs offer both psychological and physiological job resources. Psychologically, FWAs create an empowering sense of personal freedom and autonomy with regard to structuring one's work and day, supported by an encouraging signal of being cared for by the organisation (Chen \& Fulmer, 2018; Onken-Menge et al., 2018; Peretz et al., 2018). Physiologically, FWAs allow workers to work from anywhere, and at times which suit their schedule and physical circumstances best. With FWAs pervasive in the software development industry globally (Johns \& Gratton, 2013), and correlations between FWAs with engagement performance confirmed (Bailey et al., 2017), it can be argued that South African software developers who make use of FWAs are likely to measure higher on engagement and performance outcomes than those who do not.

From the preceding discussions, four specific research hypotheses are derived:

1. Hypothesis 1: FWAs are generally available to South African software developers and there will be a substantive usage of FWAs. 
2. Hypothesis 2: South African software developers perceive FWAs to be beneficial (helpful and advantageous).

3. Hypothesis 3: South African software developers who make use of FWAs are more engaged than those who do not make use of it.

4. Hypothesis 4: South African software developers who make use of FWAs experience higher performance outcomes than those who do not make use of it.

\section{Research design Research approach}

A quantitative research method was used in this cross-sectional study. Primary data were gathered via an anonymous webbased survey through a voluntary convenience sampling approach. Invitations to participate in the survey were sent via email to identified software developers in the researcher's professional network. The invitation was also posted on the researchers' LinkedIn profiles by means of the news feed facility. A participation request was also posted on the online MyBroadband forum in the discussion board for software developers. All three invitations made it clear that the researchers were only interested in the views of software developers. Responses from respondents who did not provide performance review ratings were excluded from the analyses. The study primarily focussed on analysis at the individual level, and no company-level evaluations were made (except for investigating the adoption of FWAs by employers and perceived benefit of FWAs for employers). The survey questionnaire was designed to take less than $5 \mathrm{~min}$ to complete in order to increase the potential response rate.

\section{Research method}

\section{Research participants}

A total of 277 responses were received, of which 260 responses could be used in the analyses. However, 22 respondents did not provide performance review ratings and were excluded from the performance-related analyses. Respondents represented 86 organisations, which were mostly SMEs (68\%, $n=59$ ), from seven of the nine South African provinces, with most respondents living in two provinces $(82 \%, n=210)$. Most of the respondents were 30-39 years old $(46 \%, n=119)$, followed by those younger than 30 years $(33 \%, n=84)$. Most respondents were male $(89 \%, n=230)$, with relatively few female respondents $(11 \%, n=28)$, and roughly $41 \%(n=105)$ of the respondents being parents.

\section{Measuring instruments}

Firstly, the questionnaire gathered demographic data, (e.g. age, gender, the location of participants, parental status, freelancers or fulltime employees, working hours and tenure). Secondly, three key aspects were measured, namely, engagement (Utrecht Work Engagement Scale, UWES-9), selfreported performance review and perceived benefits of FWAs (Appendix 1). Employee opinions regarding self-benefit and company benefits of FWA were determined via a five-point Likert scale questionnaire (Appendix 1). Perceptions of the benefits of the two types of FWA investigated in this study, that is, flexitime and telecommuting, were measured separately. Employee perception of self-performance was also measured via a six-point Likert scale (Appendix 1). Perception of the participant's last performance review was used as a heuristic for perceived performance.

Time at work was measured by enquiring about the typical number of hours spent in a week on work-related activities. Tenure was measured by asking respondents how many years they have been employed with their current employer. Both these questions were presented in an open-ended state to accommodate a wide range of responses.

Employee engagement was measured using the shortened version of the UWES-9 (Schaufeli, et al., 2002). The Cronbach's alphas for the 9-item UWES-9 were consistent with the original 17-item version of the UWES, which showed high internal consistency with Cronbach's alphas of $0.84,0.89$ and 0.79 for the three factors, respectively: vigour, dedication and absorption. Schaufeli et al. (2006) confirmed that UWES-9 scores have acceptable psychometric properties and that it is an acceptable instrument to measure employee engagement. The UWES-9 measures three dimensions of engagement, namely, vigour, dedication and absorption by using the same six-point Likert scale applied by Schaufeli et al. (2006).

In order to mitigate for common method variance (Fuller, Simmering, Atinc, Atinc, \& Babin, 2016), recommendations of Podsakoff, MacKenzie, Lee and Podsakoff (2003) were applied, for example, ensuring anonymity to respondents, clearly defining constructs such as flexitime and remote working, urging honest answers and the revalidation of the UWES-9 through CFA.

\section{Research procedure and ethical considerations}

The web-based survey ensured the anonymity of all participants by only providing a link to the survey, from where anonymised data were obtained on an Excel format. The survey commenced with an informed consent form, stating the rights of the participants, emphasising their voluntary participation and the right to refuse participation and to skip questions they did not feel comfortable answering. Only when participants accepted these conditions could the survey be completed. Potential participants were approached in their personal capacity and not through their respective organisations, but through the platforms and methods noted. The only organisational information collected was to ask participants to indicate their organisation's Internet domain (e.g. mycompany.co.za). Responses to this question enabled the researchers to establish organisational size by conducting a Google search. Obtaining gatekeeper permission for participants to participate in the study was therefore not deemed to be necessary.

\section{Data analyses}

In order not to compromise on data validity, only cases where respondents actually made use of FWAs, both flexitime and 
telecommuting, were included in the analyses regarding the use of FWAs. Research instruments developed elsewhere in the world do not necessarily have the same structure when applied in an emerging economy (De Klerk, Boshoff, \& Van Wyk, 2009; Van der Walt \& De Klerk, 2014). The UWES-9 was thus first validated for the South African sample in this study, through exploratory and confirmatory factor analyses.

Statistical tests used to investigate relationships included independent sample $t$-tests and Pearson's correlation. Two-sample hypothesis testing analyses were used to assess whether employees who made use of flexitime experienced higher performance outcomes than those who did not, and whether they believed FWAs would be beneficial for them or themselves, their companies and so forth. Stepwise multiple regression analysis was performed to assess the effect of FWAs on engagement and performance.

\section{Ethical consideration}

Ethical approval for this research was obtained from the Stellenbosch University Research Ethics Committee (Approval number: SU-HSD-004510).

\section{Results}

\section{Validating Utrecht Work Engagement Scale-9}

The first step in the analysis was to validate the structural validity of the UWES-9, through EFA, with maximum likelihood oblique rotation and then through CFA. Exploratory factor analysis results showed internal consistency of each factor, with Cronbach's alpha $(\alpha)>0.75$, and therefore all factors were retained. Absorption's inter-item correlation was $0.57(\alpha=0.80)$, vigour's inter-item correlation was $0.72(\alpha=0.88)$ and dedication's inter-item correlation was $0.70(\alpha=0.85)$. All factor correlations were satisfactory $(r>0.58)$. However, the high inter-item correlations of the factors indicated that some of the items might be redundant. All items loaded satisfactorily on the respective factors, except for item 7 loading on the absorption factor, rather than on dedication. Only item 5 loaded lower than $0.6(r=0.42)$.

The second step was to investigate the structural validity of the UWES-9 through CFA. The chi-square/degrees of freedom yielded 8.9 indicating a poor fit (i.e. > 3.0) (Marsh, Barnes, \& Hocevar, 1985). The root-mean-square error of approximation (RMSEA) was 0.18 , which is not considered an accurate fit by being larger than 0.08 . The normed fit index (NFI) with a value of 0.89 and the non-NFI (NNFI) with a value of 0.85 slightly missed the preferred criteria to be larger than 0.9. Both the comparative fit index (CFI) and the incremental fit index (IFI) with a value of 0.9 indicated an acceptable fit (Hu \& Bentler, 1999).

In the CFA, all the relationships were significant, but estimated errors for three items $>3.7$ suggested a restructuring of the model. Based on the EFA and the CFA, three changes to the UWES-9 model were incorporated, namely, removing items 5 and 6, and moving item 7 from dedication to factor 1
TABLE 2: Goodness-of-fit statistics for improved Utrecht Work Engagement Scale-9 model.

\begin{tabular}{lccc}
\hline Index & Value & Criteria & Result \\
\hline Chi-square divided by the degrees of freedom $(d f)$ & 1.090 & $<3$ & Pass \\
Root-mean-square error of approximation (RMSEA) & 0.019 & $<0.08$ & Pass \\
Normed fit index (NFI) & 0.993 & $>0.9$ & Pass \\
Comparative fit index (CFI) & 0.999 & $>0.9$ & Pass \\
Incremental fit index (IFI) & 0.999 & $>0.9$ & Pass \\
Standardised RMR & 0.013 & $<0.05$ & Pass \\
Goodness of fit index (GFI) & 0.988 & $>0.9$ & Pass \\
\hline
\end{tabular}

(absorption), as recommended by De Klerk et al. (2009) and Van der Walt and De Klerk (2014). Table 2 shows the main fit indices for the adjusted model.

Results from Table 2 indicate a very satisfactory fit for the improved model on all criteria. The adjusted model can thus be regarded as a valid instrument to measure engagement in this sample.

\section{Descriptive statistics}

Respondents' tenure at their current employers tended to be fairly short at 5.7 years $(n=252, \mathrm{SD}=5.6)$, although this is much longer than the 1.9 and 1.5 years reported for medium and small software development companies, respectively, in the United States (HackerLife, 2017). Software developers in this sample tended to work longer than the $40 \mathrm{~h} /$ week norm in South Africa, with the mean number of working hours being $45.3 \mathrm{~h}$ /week $(n=253, \mathrm{SD}=11.7)$. Although the mean value is higher than the norm, it is not unexpected, as it is common for highly skilled workers in South Africa to work extra hours (Van der Walt \& De Klerk, 2014).

Most respondents indicated that they have access to both flexitime and telecommuting $(78.6 \%, n=204)$, and most of these respondents $(81.6 \%, n=166)$ actually made use of both these options. These results support hypothesis 1 - FWAs are generally available to South African software developers and there will be a substantive usage of FWAs.

Respondents were asked to rate their perception of whether FWAs are beneficial on a six-point scale. Respondents indicated that they regarded FWAs as beneficial to themselves (or would be if they had access to it), with a high mean reported score of 4.75 (compared to a maximum of 6) $(n=259)$, which is the same mean as those who actually make use of it $(n=166)$. Similarly, most respondents indicated that they regarded FWAs as beneficial to companies (or would be if it was provided) with a relatively high mean reported score of 4.43 (compared to a maximum of 6$)(n=259)$, whereas those who actually made use of FWAs reported a slightly higher mean score of $4.62(n=166)$. The general perceived advantage of FWAs provides support for hypothesis 2 South African software developers perceive FWAs to be beneficial (helpful and advantageous).

The mean engagement score of the respondents was 4.35 on a five-point scale ( $\mathrm{SD}=0.92, n=260)$, without discriminating on the usage of FWAs, and 4.5 for those making use of 
FWAs. Most respondents indicated high perceptions of their performance reviews (those who used and did not use FWAs combined), with a mean reported performance score of $4.66(n=228, \mathrm{SD}=1.12)$. The analysis of variance in engagement and performance scores between those participants who actually make use of FWAs compared to those who do not are presented in the next section.

\section{Outcomes and relationships of flexible work arrangements}

Two-sample independent $t$-tests, assuming unequal variances $(p<0.05)$, were employed to assess the relationships between FWAs and years of service with employers, perceptions of FWAs being beneficial, levels of engagement and performance. In order not to compromise on data validity, analyses concerning the usage of FWAs included only cases where respondents actually made use of both flexitime and telecommuting.

The results indicate that respondents' tenure with the current employer does not differ statistically significantly for those who make use of FWAs, compared to those who do not make use of FWAs (6 and 5.4 years average, respectively; $p=0.58$ ). Even though respondents who made use of FWAs indicated that on average they worked slightly longer hours than those who did not make use of it (45.9 and 44.4 average hours per week, respectively), this difference was not statistically significant $(p=0.49)$.

Table 3 shows the $t$-test results of engagement and performance levels of respondents that make use of FWAs relative to respondents who do not.

Table 3 shows a statistically significant relative gain of $20.9 \%$ in engagement scores of respondents who make use of FWAs compared to those who do not make use of FWAs $(p<0.001)$. Table 3 also confirms that respondents who make use of FWAs report significantly higher perceived performance than those who do not $(p<0.001)$. The $13.7 \%$ gain is substantial in light of the significant benefits of engagement found by other research (Bailey et al., 2017). This result

TABLE 3: Effect of flexible work arrangements on engagement and performance.

\begin{tabular}{lcccc}
\hline Variable & FWAs used & Not used & Absolute gain & Relative gain (\%) \\
\hline Engagement & & & & \\
Mean & 4.63 & 3.83 & 0.8 & 20.9 \\
Standard deviation & 0.84 & 1.01 & - & - \\
Observations & 128 & 54 & - & - \\
$d f$ & 87 & - & - & - \\
$t$-Stat & 5.237 & - & - & - \\
$p$ & $<0.0001$ & - & - & - \\
Performance & & & & \\
Mean & 5.01 & 4.41 & 0.6 & 13.7 \\
Standard deviation & 1.03 & 1.00 & - & - \\
Observations & 105 & 54 & - & - \\
$d f$ & 110 & - & - & - \\
$t$-Stat & 3.685 & - & - & - \\
$p$ & $<0.0001$ & - & - & - \\
\hline
\end{tabular}

FWA, flexible work arrangements; $d f$, degrees of freedom. provides support for hypothesis 3 - South African software developers who make use of FWAs are more engaged than those who do not make use of it, and hypothesis 4 South African software developers who make use of FWAs experience higher performance outcomes than those who do not make use of it.

The relationship between FWAs with engagement and performance for respondents who make use of FWAs was assessed through Pearson's correlation coefficients and multiple stepwise regression. The Pearson's correlation coefficients $(r)$ between FWAs, performance and levels of engagement are indicated in Table 4.

The strongest relationship was between the use of FWAs and engagement $(r=0.38)$. The second strongest relationship was between engagement and performance $(r=0.32)$. The results in Table 4 thus confirm the statistically significant relationship of engagement with the use of FWAs (confirming hypothesis 3) as well as the significant relationship between engagement and performance. Although correlations with $r<0.3$ were generally regarded as weak and of less practical value, even if statistically significant, one can argue that the correlation between performance and the use of FWAs $(r=0.27)$ may indeed have some practical value. The reason being that profit margins of software development companies are sensitive to slight changes in the performance of software developers, and thereby have a direct impact on output. Based on this reason, hypothesis 4 is supported, but with caution.

Table 4 also indicates that the correlations of FWAs with engagement and performance are stronger when telecommuting and flexible hours are used in combination ( $r=0.38$ and 0.27 , respectively), rather than in isolation (flexible hours: $r=0.29$ and 0.16 , respectively, and telecommuting: $r=0.22$ and 0.28 , respectively). For this reason, further analyses only investigated the relationship between the combined use of telecommuting and flexible hours, with engagement and performance. Stepwise multiple regression analysis was used to assess the ability of FWAs to predict engagement and performance, with engagement as a mediating variable. These results are shown in Table 5.

Table 5 shows that utilisation of FWAs explains $14.8 \%$ of the variance in engagement $\left[R^{2}=0.148, F(1,182)=31.372\right.$, $p<0.001]$. These results confirm the results from the $t$-tests, namely, that FWAs have a significant effect on engagement

TABLE 4: Pearson's correlation coefficients.

\begin{tabular}{lccccc}
\hline Variables & $\begin{array}{c}\text { Use of } \\
\text { flexible } \\
\text { hours }\end{array}$ & $\begin{array}{c}\text { Use of } \\
\text { telecommuting }\end{array}$ & FWAs & Performance & Engagement \\
\hline FWAs use combined & - & - & 1.00 & - & - \\
Performance & $0.16^{*}$ & $0.22^{*}$ & $0.27^{*}$ & 1.00 & - \\
Engagement & $0.29^{*}$ & $0.28^{*}$ & $0.38^{*}$ & $0.32^{*}$ & 1.00 \\
\hline
\end{tabular}

FWA, flexible work arrangements. $* p<0.001$. 
TABLE 5: Regression of flexible work arrangements use, engagement and performance.

\begin{tabular}{|c|c|c|c|c|c|c|c|}
\hline \multirow[t]{2}{*}{ Predictor } & \multicolumn{3}{|c|}{ Model summary } & \multicolumn{2}{|c|}{ ANOVA } & \multicolumn{2}{|c|}{ Coefficients } \\
\hline & $R$ & $R^{2}$ & $R^{2}$ adj. & $F$ & $d f$ & Beta & $t$-Stat \\
\hline Dependent variable: Engagement & 0.39 & 0.148 & 0.144 & $31.372 * * *$ & 1 & - & - \\
\hline Observations & 182 & - & - & - & - & - & - \\
\hline Intercept & - & - & - & - & - & 0.630 & $30.568 * * *$ \\
\hline Use of FWAs & - & - & - & - & - & 0.138 & $5.601 * * *$ \\
\hline Dependent variable: Performance & 0.27 & 0.073 & 0.067 & $12.369 * * *$ & 1 & - & - \\
\hline Intercept & - & - & - & - & - & 0.735 & $31.694 * * *$ \\
\hline Use of FWAs & - & - & - & - & - & 0.100 & $3.517 * * *$ \\
\hline Dependent variable: Performance & 0.32 & 0.10 & 0.096 & $25.078 * * *$ & 1 & - & - \\
\hline Observations & 228 & - & - & - & - & - & - \\
\hline Intercept & - & - & - & - & - & 0.503 & $8.949 * * *$ \\
\hline Engagement & - & - & - & - & - & 0.387 & $5.008 * * *$ \\
\hline Dependent variable: Performance & 0.44 & 0.194 & 0.184 & $18.821 * * *$ & 2 & - & - \\
\hline Intercept & - & - & & - & - & 0.486 & $8.743 * * *$ \\
\hline Use of FWAs & - & - & - & - & - & 0.049 & $1.696 *$ \\
\hline Engagement & - & - & - & - & - & 0.394 & $4.848 * * *$ \\
\hline
\end{tabular}

ANOVA, Analysis of variance; FWA, flexible work arrangements.

${ }^{*} p<0.1 ; * * p<0.05 ; * * * p<0.001$

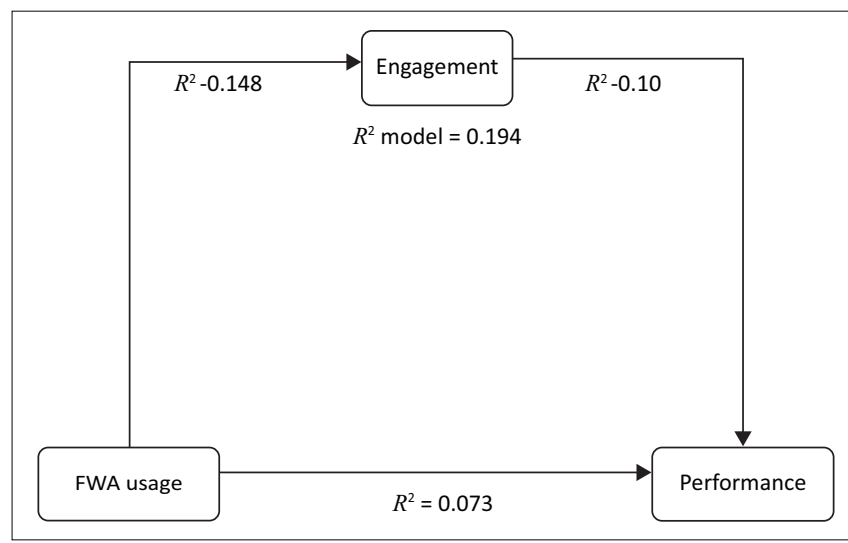

FWA, flexible work arrangements.

FIGURE 1: Research model.

and provide further support for hypothesis 2. The next step was to conduct stepwise multiple regression analysis to assess the ability of engagement to predict performance, after controlling for the influence of utilising FWAs. Utilisation of FWAs was entered at Step 1, explaining 7.3\% of the variance in performance $\left[R^{2}=0.073, F(1,159)=12.369, p<0.001\right]$. After entry of engagement at Step 2, the total variance explained by the model was $19.4 \%\left[R^{2}=0.194, F(1,228)=18.821, p<0.001\right]$. In other words, FWAs and engagement together explain $19.4 \%$ of the variance in performance, with engagement as a mediating variable explaining $10 \%$ of the variance in performance after controlling for use of FWAs $\left[R^{2}=0.10, F(2\right.$, 159) $=25.078, p<0.001]$.

The main results from the regression analysis are graphically illustrated in Figure 1.

Despite relatively low $R^{2}$ numbers, the research model (Figure 1) demonstrates that FWAs contribute to improved engagement and performance, and also that engagement is associated positively with performance. The results noted in
Table 5 and Figure 1 provide further support for both hypotheses 3 and 4 .

\section{Discussion}

The study makes important contributions to insights on workplace flexibility. This study confirms a substantive provision of FWAs by South African software development companies and the utilisation thereof by their software developers. The results confirm that FWAs contribute, similarly to what was found in developed economies, to improved engagement and performance (De Menezes \& Kelliher, 2017), and also that engagement is associated positively with performance (Böckerman \& Ilmakunnas, 2012; Thompson et al., 2015). This study confirms the importance of FWAs for software development firms in South Africa, a fast-growing sector, suffering from chronic skills shortages, and where the output of developers directly affects the products or services. The results also confirm previous research (Thompson et al., 2015) that specific FWAs are less effective when used in isolation, however, rendering a stronger result if more than one type of FWAs is applied, for example, combining flexitime with telecommuting. The South African software developers in the sample perceived FWAs to be beneficial to themselves and to their companies. This implies that employers who are considering implementing FWAs are likely to receive support from their staff.

Contrary to research findings in the United States (Spreitzer et al., 2017), the results indicate that FWAs do not necessarily influence employee tenure with an organisation in South Africa, with the tenure apparently longer in this sample than what was found in the United States (Spreitzer et al., 2017). This can arguably be a result of less favourable employment opportunities in the macroeconomic context of the emerging economy, notwithstanding potential skills shortages in this context. Although one must be careful not to make confirmed conclusions or equate employee tenure with turnover 
intentions, this result does put a question mark behind whether FWAs influence turnover in an emerging economy, as found in other studies (McNall et al., 2010).

This study did not find a statistically significant difference in the working hours of developers who make use of FWAs in comparison to those who do not make use of it, although the former indicated more working hours per week on average. This result signals that employers do not need to be concerned that less control over employees who work from home or choosing their own hours, will put in fewer hours of work. Although working hours do not equate to work-life balance, this result nevertheless puts a question mark behind whether FWAs actually influence work-life balance in this emerging economy, as found elsewhere (Spreitzer et al., 2017).

The study also confirms the statistically significant correlation between FWAs and engagement. Engagement, which positively correlates with FWAs, also acts as a mediating variable to explain some of the variance in performance in the research model. Although the explanation percentages in the research model are somewhat low, combined with the Pearson's correlation and $t$-tests, the results provide significant support for the important correlations between FWAs with engagement and performance for the South African sample of software developers. With employee engagement generally a strong predictor of performance and many other positive work outcomes, as was found by other research (Bailey et al., 2017), even slight increases in developers' engagement are important to competitive software developing entities.

\section{Limitations and future studies}

As with any research project, this study is also subject to limitations. The study did not make a full provision for selfselection bias and common method variance. The voluntary nature of online surveys arguably might have resulted in software developers who are more interested, positive or involved in FWAs volunteering for the study. As convenience sampling was used, the sample is not necessarily representative of the South African population of software developers and could even include people who are not software developers or working in the software development industry. The sample is relatively small and concentrated in the small- to medium-sized software development companies within South Africa. One should therefore be careful not to make any unqualified generalisations about the benefits of FWAs to other organisations, other industries, other types of employees, even within this industry and to other emerging economies. However, not only were several mitigation measures applied to prevent common method variance as noted but also the high response to invitation ratio potentially indicate mitigation (Podsakoff et al., 2003). As such, we argue that Fuller et al.'s (2016) finding that common method variance does not represent a grave threat to the validity of research findings apply in this case.

The study can be improved by introducing a control group. Usage of only two types of FWAs was measured, namely, flexitime and telecommuting. The results, therefore, do not necessarily apply to other types of FWAs or workplace flexibilities. The respective use of flexitime and telecommuting was not split in the measurement, but measured together. This reduces the ability to distinguish between the use and the effect of these two types of FWAs. Performance was approximated through measuring satisfaction with performance review and not actual performance. More research and more comprehensive studies are recommended on the outcomes of FWAs (and separately for different types of FWAs such as flexitime and telecommuting), focussing on other industries, other kinds of employees, other aspects of workplace flexibility and other emerging economies.

\section{Contributions of study and recommendations to organisations}

Workplace flexibility and FWAs are not only receiving increasing exposure and interest but are potentially effective ways to address many workplace concerns and improve individual and organisational functioning. The results confirm that in this emerging economy, outcomes of FWAs do not necessarily differ from more developed economies. This finding is important in the light of critical shortage and resulting high pressure on software developers in this context (News24Wire, 2015). This study confirms that the prevalence and usage of FWAs have a relevant and positive relationship with employee engagement and self-reported performance in software development companies in South Africa. Results from this study are important as they provide significant evidence that the FWAs can yield positive work outcomes, and should be encouraged where practical and appropriate. It is therefore recommended that employers that do not currently make use of FWAs should at least consider implementing flexitime and telecommuting. This recommendation does not only apply to South African organisations in the software development industry, but perhaps also to other industries and other emerging economies as well.

\section{Conclusion}

The benefits identified from implementing or using FWA are significant, whereas the risk of implementing FWA appears to be low. Apart from being associated with higher engagement and perceived performance levels, the adaptability to circumstances that flexitime and telecommuting offer individuals and potential employees potentially enable companies to recruit from a much larger talent pool. Flexible work arrangements can potentially also reduce high costs associated with workplace space constraints and relocation. South African software development employers, and perhaps also other emerging economies, that are still considering FWA can probably implement it with confidence and are likely to receive support from their staff.

\section{Acknowledgements}

The authors would like to thank Prof. Charlene Gerber for assistance with statistical analyses. 


\section{Competing interests}

The authors confirm that this work is original and has not been published elsewhere, nor is it currently under consideration for publication elsewhere.

\section{Authors' contributions}

W.J.C. conducted the research and analyses, and contributed to manuscript writing. J.J.D.K. provided guidance and support for the research and analyses, and contributed to the final manuscript.

\section{Funding information}

This research received no specific grant from any funding agency in the public, commercial or not-for-profit sectors.

\section{Data availability statement}

Data can be made available on request.

\section{Disclaimer}

The views expressed in this article are the authors' own and not an official position of the institution or the funder.

\section{References}

Abba, H.D. (2018). Flexitime and performance of academic staff in polytechnics in north west geo-political zones of Nigeria. KIU Journal of Social Sciences, 4(2), 123-130. https://doi.org/10.15406/ahoaj.2018.02.00056

Abbot, P. (2014). Employee engagement: Fact sheet. Retrieved from http://sabpp. co.za/sabpp-fact-sheets/.

Ahmad, A., Shaw, N.E., Bown, N.J., Gardiner, J., \& Omar, K. (2015). The impact of negative work home interface on intention to leave and the role of flexible working arrangements in Malaysia. The Journal of Developing Areas, 50(5) 507-515. https://doi.org/10.1353/jda.2016.0066

Allen, T.D., Golden, T.D., \& Shockley, K.M. (2015). Commentary on: How effective is telecommuting? Assessing the status of our scientific findings. Psychological Science in the Public Interest, 16(2), 38-39. https://doi.org/10.1177/1529100 615593273

Allen, T.D., Johnson, R.C., Kiburz, K.M., \& Shockley, K.M. (2013). Work-family conflict and flexible work arrangements: Deconstructing flexibility. Personnel Psychology, 66(2), 345-376. https://doi.org/10.1111/peps.12012

Anitha, J. (2014). Determinants of employee engagement and their impact on employee performance. International Journal of Productivity and Performance Management, 63(3), 308-323. https://doi.org/10.1108/IJPPM-01-2013-0008

Appiah-Mfodwa, A., Horwitz, F., Kieswetter, G., King, D., \& Solai, L. (2000). Flexible work practices, productivity improvement and employment. Society in Transition, 31(2), 95-110. https://doi.org/10.1080/21528586.2000.10419016

Ayman, M., Ashoush, A.-L., \& Younis, R.A. (2015). Flexible work arrangements: Related topics and directions. Journal of Business Studies Quarterly, 7(1), 36-45.

Baard, N., \& Thomas, A. (2010). Teleworking in South Africa: Employee benefits and challenges. SA Journal of Human Resource Management, 8(1), 1-10. https://doi. org/10.4102/sajhrm.v8i1.298

Bailey, C., Madden, A., Alfes, K., \& Fletcher, L. (2017). The meaning, antecedents and outcomes of employee engagement: A narrative synthesis. International Journa of Management Reviews, 19(1), 31-53. https://doi.org/10.1111/ijmr.12077

Bal, P.M., \& De Lange, A.H. (2015). From flexibility human resource management to employee engagement and perceived job performance across the lifespan: A multisample study. Journal of Occupational and Organizational Psychology, 88(1), 126-154. https://doi.org/10.1111/joop.12082

Berkery, E., Morley, M.J., Tiernan, S., Purtill, H., \& Parry, E. (2017). On the uptake of flexible working arrangement and the association with human resource and organizational performance outcomes. European Management Journal, 14 165-183. https://doi.org/10.1111/emre.12103

Bessa, I., \& Tomlinson, J. (2017). Established, accelerated and emergent themes in flexible work research. Journal of Industrial Relations, 59(2), 153-169. https://doi. org/10.1177/0022185616671541

Bloom, N., Liang, J., Roberts, J., \& Ying, Z.J. (2015). Does working from home work? Evidence from a Chinese experiment. Quarterly Journal of Economics, 130(1), 165-218. https://doi.org/10.1093/qje/qju032
Böckerman, P., \& Ilmakunnas, P. (2012). The job satisfaction-productivity nexus: A study using matched survey and register data. Industrial and Labor Relations study using matched survey and register data. Industrial and Labor
Review, 65(2), 244-262. https://doi.org/10.1177/001979391206500203

Boell, S.K., Cecez-Kecmanovic, D., \& Campbell, J. (2016). Telework paradoxes and practices: The importance of the nature of work. New Technology, Work and Employment, 31(2), 114-131. https://doi.org/10.1111/ntwe.12063

Campbell, K.M. (2015). Flexible work schedules, virtual work programs, and employee productivity. Doctoral dissertation. Minneapolis, MN: Walden University.

Chandra, V. (2012). Work-life balance: Eastern and western perspectives. The International Journal of Human Resource Management, 23(5), 1040-1056. https://doi.org/10.1080/09585192.2012.651339

Chen, Y., \& Fulmer, I. (2016). Fine-tuning what we know about flexible work arrangements: Deconstructing employees' experience. Academy of Management Proceedings, 2016(1), 1-23. https://doi.org/10.5465/ambpp.2016.270

Chen, Y., \& Fulmer, I.S. (2018). Fine-tuning what we know about employees experience with flexible work arrangements and their job attitudes. HR Science Forum, 57, 381-395. https://doi.org/10.1002/hrm.21849

Ciarniene, R., \& Vienazindiene, M. (2018). Flexible work arrangements from generation and gender perspectives: Evidence from Lithuania. Inzinerine EkonomikaEngineering Economics, 29(1), 84-92. https://doi.org/10.5755/j01.ee.29.1.19247

Coenen, M., \& Kok, R.A.W. (2014). Workplace flexibility and new product development performance: The role of telework and flexible work schedules. European Management Journal, 32(4), 564-576. https://doi.org/10.1016/j.emj.2013.12.003

Croucher, R., \& Rizov, M. (2014). MNEs and flexible working practices in Mauritius. The International Journal of Human Resource Management, 26(21), 2701-2717. https://doi.org/10.1080/09585192.2014.934898

De Klerk, J.J., Boshoff, A.B., \& Van Wyk, R. (2009). Measuring meaning in life in South Africa: Validation of an instrument developed in the USA. South African Journal of Psychology, 39(3), 314-325. https://doi.org/10.1177/008124630903900306

De Menezes, L.M., \& Kelliher, C. (2011). Flexible working and performance: A systematic review of the evidence for a business case. International Journal of Management Reviews, 13(4), 452-474. https://doi.org/10.1111/j.1468-2370. 2011.00301.x

De Menezes, L.M., \& Kelliher, C. (2017). Flexible working, individual performance, and employee attitudes: Comparing formal and informal arrangements. Human Resource Management, 56(6), 1051-1070. https://doi.org/10.1002/hrm.21822

Den Dulk, L., Groeneveld, S., Ollier-Malaterre, A., \& Valcour, M. (2013). National context in work-life research: A multi-level cross-national analysis of the adoption of workplace work-life arrangements in Europe. European Management Journal, 31(5), 478-495. https://doi.org/10.1016/j.emj.2013.04.010

Dizaho, E.K., Salleh, R., \& Abdullah, A. (2017). Achieving work life balance through flexible work schedules and arrangements. Global Business and Management: An International Journal, 9(1), 455-466.

Fuller, C.M., Simmering, M.J., Atinc, G., Atinc, Y., \& Babin, B.J. (2016). Common methods variance detection in business research. Journal of Business Ethics, 69, 3192-3198. https://doi.org/10.1016/j.jbusres.2015.12.008

Grobler, P.A., \& De Bruyn, A.J. (2011). Flexible work practices (FWP) - An effective instrument in the retention of talent: A survey of selected JSE-listed companies. South African Journal of Business Management, 42(4), 63-78. https://doi. org/10.4102/sajbm.v42i4.506

Haar, J.M., Russo, M., Suñe, A., \& Ollier-Malaterre, A. (2014). Outcomes of work-life balance on job satisfaction, life satisfaction and mental health: A study across seven cultures. Journal of Vocational Behavior, 85(3), 361-373. https://doi. org/10.1016/j.jvb.2014.08.010

HackerLife. (2017). Software engineers tenure in San Francisco. Retrieved from https://hackerlife.co/blog/san-francisco-large-corporation-employee-tenure.

Halpern, D.F. (2005). How time-flexible work policies can reduce stress, improve health, and save money. Stress and Health, 21(3), 157-168. https://doi.org/ 10.1002/smi.1049

Horwitz, F. (2017). International HRM in South African multinational companies. Journal of International Management, 23(2), 208-222. https://doi.org/10.1016/j. intman.2017.01.005

Hu, L., \& Bentler, P.M. (1999). Cutoff criteria for fit indexes in covariance structure analysis: Conventional criteria versus new alternatives. Multidisciplinary Journal, 6(1), 1-55. https://doi.org/10.1080/10705519909540118

Idris, A. (2014). Flexible working as an employee retention strategy in developing countries: Malaysian bank managers speak. Journal of Management Research, 14(2), 71-86.

Johns, T., \& Gratton, L. (2013). The third wave of virtual work. Harvard Business Review, 91(1-2), 1-9.

Kassinis, G.I., \& Stavrou, E.T. (2013). Non-standard work arrangements and national context. European Management Journal, 31, 464-477. https://doi.org/10.1016/j. emj.2013.04.005

Lee, J., \& De Kok, A. (2016). The new way of working: Bricks, bytes and behavior. In L. Jungwoo (Ed.), The impact of ICT on work (pp. 9-40). Seoul: Springer Singapore.

Lockwood, N.R. (2007). Leveraging employee engagement for competitive advantage. Research Quarterly, 52(3), 1-12.

Marsh, H.W., Barnes, J., \& Hocevar, D. (1985). Self-other agreement on multidimensional self-concept ratings: Factor analysis and multitrait-multimethod analysis. Journal of Personality and Social Psychology, 49(5), 1360-1377. https:// doi.org/10.1037/0022-3514.49.5.1360

Maseko, F. (2017). South African software developers are in high demand. Retrieved from http://www.itnewsafrica.com/2017/09/south-african-software-developersare-in-high-demand/. 
Masuda, A.D., Poelmans, S.A.Y., Allen, T.D., Spector, P.E., Lapierre, L.M., Cooper, C.L., ... Moreno-Velazquez, I. (2012). Flexible work arrangements availability and their relationship with work-to-family conflict, job satisfaction and turnover intentions. Applied Psychology: An International Review, 61(1), 1-29. https://doi.org/ 10.1111/j.1464-0597.2011.00453.x

McNall, L.A., Masuda, A.D., \& Nicklin, J.M. (2010). Flexible work arrangements, job satisfaction, and turnover intentions: The mediating role of work-to-family enrichment. The Journal of Psychology, 144(1), 61-81. https://doi.org/10.1080/ enrichment. The Journa

Naidoo, S., \& Kasiram, M. (2003). Experiences of South African social workers in the United Kingdom. Social Work/Maatskaplike Werk, 42(2), 117-126. https://doi. org/10.15270/42-2-306

News24Wire. (2015). Shortage of skilled workers in South Africa. Retrieved from http://businesstech.co.za/news/it-services/87740/shortage-of-skilled-workersin-south-africa/.

Nortje, H., Van Brakel, P.A., \& Rensleigh, C. (2009). Information environment of teleworkers in South Africa. SA Journal of Information Management, 6(1), 1-16. https://doi.org/10.4102/sajim.v6i1.294

Ollier-Malaterre, A., \& Foucreault, A. (2017). Cross-national work-life research Cultural and structural impacts for individuals and organizations. Journal of Management, 43(1), 111-136. https://doi.org/10.1177/0149206316655873

Onken-Menge, G., Nüesch, S., \& Kröll, C. (2018). Are you attracted? Do you remain? Meta-analytic evidence on flexible work practices. Business Research, 11, 239-277. https://doi.org/10.1007/s40685-017-0059-6

Opuko, H., \& Munjuri, M.G. (2017). Flexible work practices and job performance in the transport and logistics industry: The Kenyan perspective. DBA Africa Managemen Review, 7(2), 78-92.

Peretz, H., Fried, Y., \& Levi, A. (2018). Flexible work arrangements, national culture, organisational characteristics, and organisational outcomes: A study across 21 countries. Human Resource Management Journal, 28, 182-200. https://doi. org/10.1111/1748-8583.12172

Perlow, L.A., \& Kelly, E.L. (2014). Toward a model of work redesign for better work and better life. Work and Occupations, 41(1), 111-134. https://doi.org/10.1177/ 0730888413516473

Peters, P., \& Den Dulk, L. (2003). Cross cultural differences in managers' support for homebased telework: A theoretical elaboration. International Journal of Cross Cultural Management, 3(3), 329-346. https://doi.org/10.1177/1470595803003003005.

Pitt-Catsouphes, M., Matz-Costa, C., \& Besen, E. (2012). Workplace flexibility - Issue brief. Retrieved from https://www.bc.edu/research/agingandwork/archive_pubs/ IB19.html.

Podsakoff, P.M., MacKenzie, S.B., Lee, J.Y., \& Podsakoff, N.P. (2003). Common method biases in behavioral research: A critical review of the literature and recommended remedies. Journal of Applied Psychology, 88(5), 879-903. https://doi.org/10.1037/ 0021-9010.88.5.879

Putnam, L.L., Myers, K.K., \& Gailliard, B.M. (2014). Examining the tensions in workplace flexibility and exploring options for new directions. Human Relations, 67(4), 413-440. https://doi.org/10.1177/0018726713495704

Quartz Africa. (2016). South Africa doesn't have enough developers to build a digital economy. Retrieved from https://qz.com/714662/south-africa-doesnt-haveenough-developers-to-build-a-digital-economy/

Rabl, T., Jayasinghe, M., Gerhart, B., \& Kühlmann, T.M. (2014). A meta-analysis of country differences in the high-performance work system-business performance relationship: The roles of national culture and managerial discretion. Journal of Applied Psychology, 99(6), 1011-1041. https://doi.org/10.1037/a0037712

Reddy, V., Bhorat, H., Powell, M., Visser, M., \& Arends, F. (2016). Skills supply and demand in South Africa. Pretoria: Department of Higher Education and training.
Regus. (2017). The workplace revolution: A picture of flexible working 2017. Retrieved from https://www.regus.co.za/work-southafrica/wp-content/uploads/ sites/131/2017/06/GBS-Report.pdf.

Ross, P., \& Ali, Y. (2017). Normative commitment in the ICT sector: Why professional commitment and flexible work practices matter. International Journal of Employment Studies, 25(1), 44-63.

Schaufeli, W.B., \& Bakker, A.B. (2004). Job demands, job resources, and their relationship with burnout and engagement: A multi-sample study. Journal of Organizational Behavior, 25(3), 293-315. https://doi.org/10.1002/job.248

Schaufeli, W.B., Salanova, M., González-romá, V.A., \& Bakker, A.B. (2002). The measurement of engagement and burnout: $A$ two sample confirmatory factor analytic approach. Journal of Happiness Studies, 3, 71-92. https://doi.org/ 10.1023/A:1015630930326

Spreitzer, G.M., Cameron, L., \& Garrett, L. (2017). Alternative work arrangements: Two images of the new world of work. Annual Review of Organizational Psychology and Organizational Behavior, 4(1), 473-499. https://doi.org/10.1146/annurevorgpsych-032516-113332

Statistics South Africa. (2017). Three facts about the ICT sector. Retrieved from http:// www.statssa.gov.za/?p=9852.

Stavrou, E.T. (2005). Flexible work bundles and organizational competitiveness: A cross-national study of the European work context. Journal of Organizational Behavior, 26(8), 923-947. https://doi.org/10.1002/job.356

Stavrou, E.T., \& Kilaniotis, C. (2010). Flexible work and turnover: An empirical investigation across cultures. British Journal of Management, 21, 541-554.

Stavrou, E.T., Parry, E., \& Anderson, D. (2015). Nonstandard work arrangements and configurations of firm and societal systems. The International Journal of Human Resource Management, 26(19), 2412-2433. https://doi.org/10.1111/j.14678551.2009.00659.x

Stock, R.M., Strecker, M.M., \& Bieling, G.I. (2016). Organizational work-family support as universal remedy? A cross-cultural comparison of China, India and the USA. The International Journal of Human Resource Management, 27(11), 1192-1216. https://doi.org/10.1080/09585192.2015.1062039

Subramaniam, G., Tan, P.-L., Maniam, B., \& Ali, E. (2013). Workplace flexibility, empowerment and quality of life. Procedia - Social and Behavioral Sciences, 105 885-893. https://doi.org/10.1016/j.sbspro.2013.11.090

Ter Hoeven, C.L., \& Van Zoonen, W. (2015). Flexible work designs and employee wellbeing: Examining the effects of resources and demands. New Technology, Work and Employment, 30(3), 237-255. https://doi.org/10.1111/ntwe.12052

Thompson, R.J., Payne, S.C., \& Taylor, A.B. (2015). Applicant attraction to flexible work arrangements: Separating the influence of flextime and flexplace. Journal of Occupational and Organizational Psychology, 88(4), 726-749. https://doi.org/ 10.1111/joop.12095

Timms, C., Brough, P., O’Driscoll, M., Kalliath, T., Siu, O.L., Sit, C., \& Lo, D. (2015). Flexible work arrangements, work engagement, turnover intentions and psychological health. Asia Pacific Journal of Human Resources, 53(1), 83-103. https://doi. org/10.1111/1744-7941.12030

Vahle-Hinz, T., Kirschner, K., \& Thomson, M. (2013). Employment-related demands and resources - New ways of researching stress in flexible work arrangements. Management Revue, 24(3), 199-221. https://doi.org/10.5771/0935-9915-2013-3-199

Van der Walt, F., \& De Klerk, J.J. (2014). Measuring spirituality in South Africa: Validation of instruments developed in the USA. International Review of Psychiatry, 26(3), 368-378. https://doi.org/10.3109/09540261.2014.907129

Weale, V.P., Wells, Y.D., \& Oakman, J. (2017). Flexible working arrangements in residential aged care: Applying a person-environment fit model. Asia Pacific Journa of Human Resources, 55(3), 356-374. https://doi.org/10.1111/1744-7941.12142 


\section{Appendix 1}

Items from the survey questionnaire (excluding Utrecht Work Engagement Scale-9 and demographic items)

1. I can work flexible hours? (Yes, and I am using it; Yes, but not using it; No)

2. I have permission to work from home or remotely? (Yes, and I am using it; Yes, but not using it; No)

3. The following items relating to FWAs were measured on a five-point Likert scale ( $1=$ Never; 5 = Always)
a. I think flexitime is (or would be) beneficial for my company
b. I think flexitime is (or would be) beneficial for myself
c. I think working from home or remotely is (or would be) beneficial for my company
d. I think working from home or remotely is (or would be) beneficial for myself

4. If not a freelancer, how would you rate your last performance review? (seven-point scale, $0=$ Terrible; $6=$ Great) 